INFLUENCE OF PARENTAL EMPLOYMENT, GRADE AND GENDER ON EMOTIONAL MATURITY OF ADOLESCENTS

\author{
K. YASHODA ${ }^{1} \&$ T. KALYANI DEVI ${ }^{2}$ \\ ${ }^{1}$ Research Associate, Child Development, All India Coordinated Research Project on Home Science, Professor \\ Jaya Shankar Telangana State Agricultural University, Rajendranagar, Hyderabad, India \\ ${ }^{2}$ Professor, Human Development and Family Studies, Department of Home Science, Sri Padmavathi Mahila
}

Vishwavidyalayam, Tirupathi. Andhra Pradesh, India

ABSTRACT
The present research study was undertaken to assess and compare the emotional maturity of adolescents in
relation to their gender, grade and parental employment. The sample consisted of 480 adolescent students studying in
8th, 9 th and 10th standards from Hyderabad district out of which 240 are male students and the remaining 240 are
female students. Emotional maturity scale was given by Dr. Yashvir Sinha and Mahesh Bhargava. The obtained data
was analyzed using means S.D and 't'-test concepts. The result revealed that there was a significant difference found
between the emotional maturities of grade wise students and also between emotional maturity of adolescent male and
female students. It was also found that there was no significant difference between emotional maturities by parental
employment of adolescent.
KEYWORDS: Parental Employment, Grade, Gender, Emotional Maturity \& Adolescence

Received: Jun 29, 2017; Accepted: Jul 25, 2017; Published: Aug 02, 2017; Paper Id.: IJEEFUSAUG20171

\title{
INTRODUCTION
}

"Adolescence" means "to grow to maturity". Maturity as per definition is helpful to point out in detail the striking differences between adolescent and mature emotional attitudes. The mentality of the adolescent can best be understood, if we consider this basic difference between the faster biological and the slower psychological maturation.

The superior features of adolescence are awkwardness and insecurity, which often make a comical effect. Here is a young man or woman, biologically full-grown, but in many respects emotionally still a child. They do not know what to do with their hands and feet, there is a lack of spontaneity in their movements and speech and a constant effort to overcome their own feeling of awkwardness.

Subramanian, and Veliappan (2013) conducted a study on emotional maturity of high school students to find out whether there is any significant difference in Emotional Maturity of high school students with respect to gender and type of school. The investigator used the stratified random sampling technique for selecting the sample. The investigator selected 335 high school students from Tenkasi Taluk.). The investigator found that the high school boys and private high school students are emotionally matured.

Subbarayan and Visvanathan (2011) attempted a study to measure the emotional maturity of college students. The result of the study indicated that the emotional maturity of college students is extremely unstable. It 
is concluded that the family type, sex and the community did not play any role in the emotional maturity of the college students.

Kalyani and Maheswari (2011) examined emotional maturity of adolescents in scheduled tribes and non - tribes and also the grade differences.. The findings of the study revealed significant grade differences in the emotional maturity of non - tribal adolescents.

Suneetha and Vijayalaxmi (2007) find out the impact of maternal employment on the self concept, emotional maturity and achievement motivation of adolescents. The sample consisted of 75 adolescents of employed mothers and 75 adolescents of home makers, studying in 8th and 9th standards in Hubli- Dharwad cities of north Karnataka. Children's self concept scale by Ahulwalia, emotional maturity scale by Singh and Bhargava was used. It was also known that children of employed mothers had high emotional maturity and female children of employed mothers are highly achievement oriented.

A study reported by Kanchana (2005) on emotional maturity of adolescents of private and municipal schools, revealed no significant differences in the various dimensions of emotional maturity of adolescents of different grades.

\section{OBJECTIVES OF THE STUDY}

- To find out the influence of parental employment on Emotional maturity of adolescents.

- To know the grade differences in Emotional maturity of adolescents.

- To examine the gender differences in Emotional maturity of adolescents.

\section{HYPOTHESES}

\section{The Following Hypotheses Were Tested in the Present Study}

- There is no significant difference between Emotional Maturity by parental employment.

- There is a significant difference between Emotional Maturity by grade of adolescents.

- There is a significant difference between Emotional Maturity by gender of adolescents.

\section{METHODOLOGY}

Research Method: Descriptive survey method was used.

Sample: Sample of 480 adolescents. They were selected randomly from 8th, 9th, 10th grades of Private schools in Hyderabad city. The sample included 240 boys and 240 girls and their parents.

Tools Used: To measure emotional maturity of the respondents, the scale developed by Singh and Bhargava (2011) was used. This scale measures the different aspects of emotional maturity. The dimensions of the scale are Emotional unstability, Emotional regression, Social maladjustment, Personality disintegration, and Lack of independence. Emotional maturity scale has a total of 48 items and distribution over 5 dimensions. Emotional unstability has 10 items, emotional regression has 10 items, social maladjustment has 10 items and personality disintegration has 10 items and lack of independence has 8 items.

Statistical Analysis: Percentages, Mean, S.D, 't'-test and analysis of variance (ANOVA) was used for data analysis. 


\section{RESULTS AND DISCUSSIONS}

The results of the study were presented below:

The results shown in table 1 revealed that there was no significant difference in their emotional maturity between parents with software and non software adolescents. Hence, the hypothesis formulated was proved. The results clearly stated that there was no difference in the emotional maturity of adolescents with parents of software and non software, which indicates that in both the groups are giving equal importance to their adolescents for expression of their emotions. Hence they achieved the emotional maturity in a similar fashion.

Table 1: Emotional Maturity Scores of Adolescent by Parental Employment

\begin{tabular}{|c|l|c|c|c|c|}
\hline S. No. & Parental Employment & N & Mean & SD & 't' Value \\
\hline 1 & Non Software & 240 & 193.06 & 15.75 & \\
2 & Software & 240 & 193.81 & 18.93 & 0.47 NS \\
\hline \multicolumn{4}{|l}{ NS- Not significant }
\end{tabular}

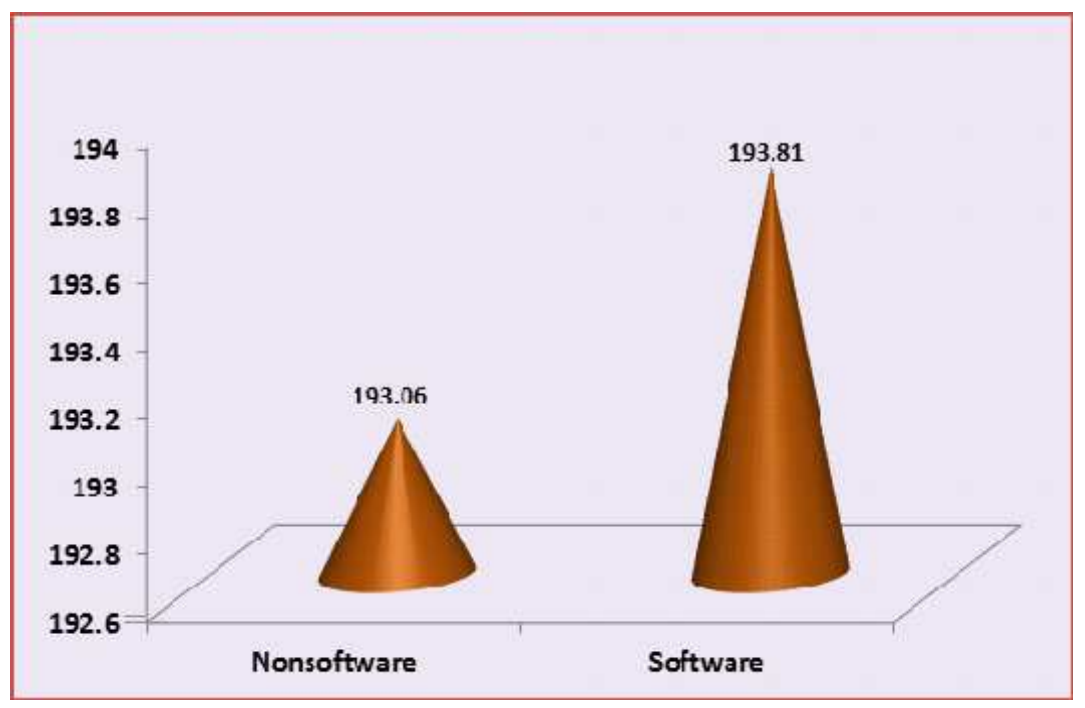

Figure 1: Emotional Maturity of Adolescents by Parental Employment

Table 2 represents the Mean, SD's and 'F' values of emotional maturity of adolescents from different grades. The Mean values of different grades i.e $8^{\text {th }}, 9^{\text {th }}$ and $10^{\text {th }}$ were $189.95,194.64$ and 195.71 respectively. The corresponding SD values were $18.13,16.58$ and 17.04. It is observed that the mean emotional maturity was high in $10^{\text {th }}$ grade adolescents followed by $9^{\text {th }}$ grade. The mean emotional maturity was low in $8^{\text {th }}$ grade students compared to others. The ' $F$ ' value $(\mathrm{F}=5.04, \mathrm{P}<0.01)$ being significant indicates the significant difference between the emotional maturity of adolescents belonging to different grades. Hence the hypothesis was rejected.

Table 2: Emotionl Maturity of Adolescents in Relation to Grade

\begin{tabular}{|c|c|c|c|c|}
\hline S. No & Grade & Mean & SD & 'F' Value \\
\hline 1 & $8^{\text {th }}$ grade & 189.95 & 18.13 & \multirow{3}{*}{$5.04 * *$} \\
\hline 2. & $9^{\text {th }}$ grade & 194.64 & 16.59 & \\
\hline 3. & $10^{\text {th }}$ grade & 195.71 & 17.04 & \\
\hline
\end{tabular}




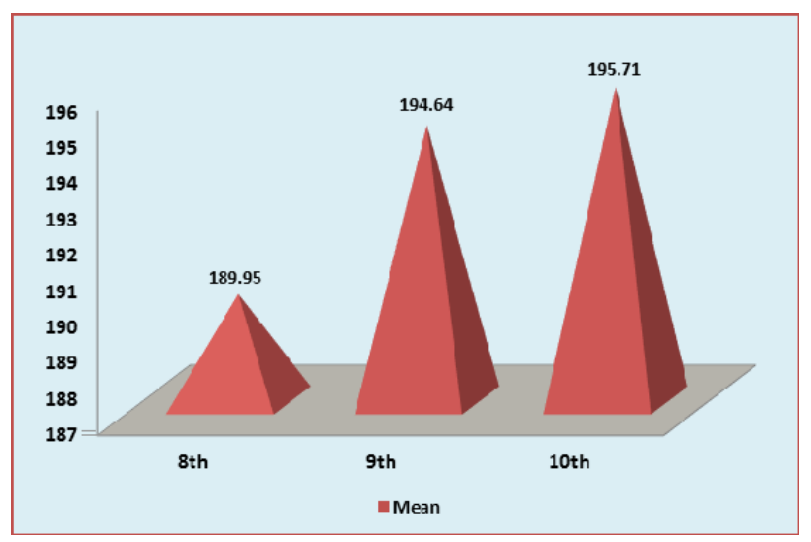

Figure 2: Emotional Maturity of Adolescents by Grade

The mean values of girls and boys for emotional maturity were 204.23 and 183.75 respectively. The mean emotional maturity scores of girls were high, when compared to mean scores of boys. It is however interesting to note that gender variation has shown significant difference in the total emotional maturity. The corresponding SD values for girls and boys were 14.22 and 13.98. The ' $\mathrm{t}$ ' Value which was significant $(\mathrm{t}=15.89 * * \mathrm{p}<0.01)$ also shown the difference in emotional maturity of adolescent boys and girls and the hypothesis was rejected.

In the present study, the mean scores of boys were low and this means that boys were high in emotional maturity (The higher the score, the lower the emotional maturity).

Table 3: Mean Emotional Maturity Scores of Boys and Girls

\begin{tabular}{|c|l|c|c|c|c|}
\hline S. No & Gender & N & Mean & SD & 'T' Value \\
\hline 1. & Boys & 253 & 204.23 & 14.22 & \multirow{2}{*}{$15.89 * *$} \\
\hline 2. & Girls & 227 & 183.75 & 13.98 & \\
\hline
\end{tabular}

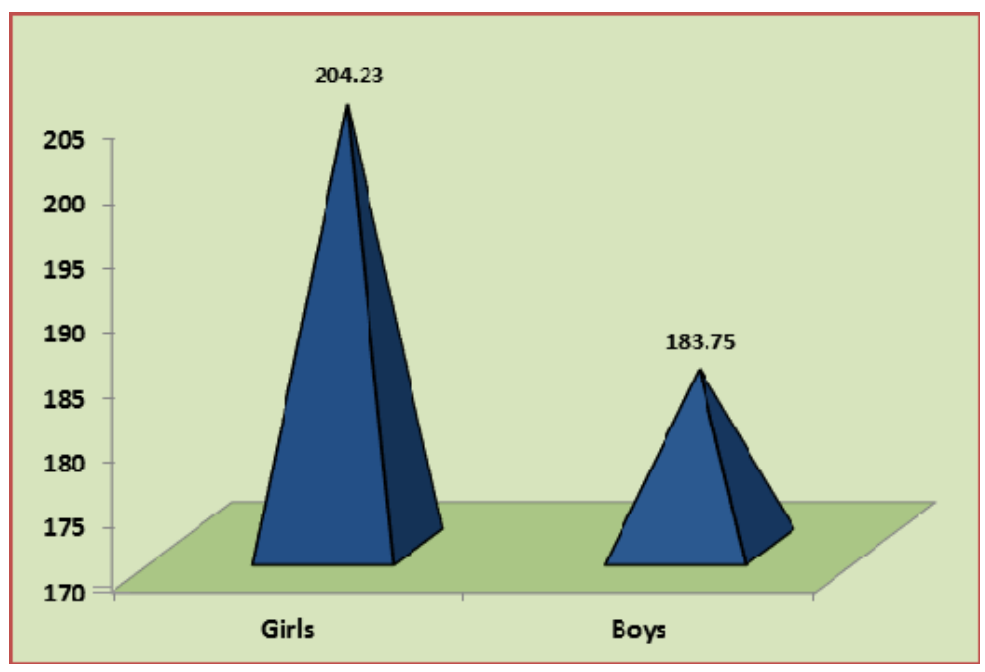

Figure 3: Emotional Maturity of Adolescents by Gender

\section{CONCLUSIONS}

From the above study, it was concluded that there was a significant difference found between the emotional maturities of grade wise and also between emotional maturity of adolescent male and female students, it was also found that there was no significant difference between social maturities by parental employment. 
It was also concluded that $10^{\text {th }}$ grade students had higher maturity than $8^{\text {th }}$ and $9^{\text {th }}$, and male adolescent students had higher emotional maturity than female adolescents, when compared.

\section{EDUCATIONAL IMPLICATIONS}

The educational planners, psychologists and human resource development specialists should plan the programmes for parents and adolescents, highlighting the importance of adolescent period for an individual to turn in to a successful adult with particular reference to the development of emotional maturity, which leads to healthy personality development.

\section{REFERENCES}

1. Kalyani, $T$ and Maheswari. (2011). Emotional maturity of adolescents in scheduled tribes and non tribes. Journal of Psycho Linguistic Association of India. 41(2): 182-184.

2. Kanchana, G. (2005). Emotional maturity of adolescents of Private and Municipal schools. 49-50.

3. Singh Y and Bhargava M. (2011). Manual for revised Emotional Maturity Scale. Agra: National Psychological Corporation

4. Subbarayan, $K$ and Visvanathan, G. (2011). A study on emotional maturity of college students. Recent Research in Science and Technology. 3(1): 153-155.

5. Subramanian, $N$ and Veliappan, A. (2013). A study on emotional maturity of high school student. Indian Journal of Applied Research. 3(11): 142-143.

6. Suneetha, H and Vijayalaxmi, A.A. (2007). Self-concept, emotional maturity and achievement motivation of the adolescent children of employed mothers and homemakers. Journal of the Indian Academy of Applied Psychology. 33(1): 103-110. 
